\title{
The effects of surface tension on the spreading ratio during the impact of multiple droplets onto a hot solid surface
}

\author{
Rafil Arizona ${ }^{1, *}$, Teguh Wibowo ${ }^{1,2}$, Indarto Indarto ${ }^{1,3}$, and Deendarlianto Deendarlianto ${ }^{1,3}$ \\ ${ }^{1}$ Universitas Gadjah Mada, Faculty of Engineering, Department of Mechanical and Industrial Engineering, Jl. Grafika No. 2 Yogyakarta \\ 55281 Indonesia \\ ${ }^{2}$ Adisucipto Technology College, Department of Mechanical Engineering, Blok R Lanud Adisutjipto Yogyakarta 55198 Indonesia \\ ${ }^{3}$ Universitas Gadjah Mada, Center for Energy Studies, Sekip Blok K 1A Yogyakarta 55281 Indonesia
}

\begin{abstract}
The impact between multiple droplets onto hot surface is an important process in a spray cooling. The present study was conducted to investigate the dynamics of multiple droplet impact under various surface tensions. Here, the ethylene glycol with compositions of $0 \%, 5 \%$, and $15 \%$ was injected through a nozzle onto stainless steel surface as the multiple droplet. The solid surface was heated at the temperatures of $100{ }^{\circ} \mathrm{C}, 150{ }^{\circ} \mathrm{C}$, and $200{ }^{\circ} \mathrm{C}$. To observe the dynamics of multiple droplets, a high speed camera with the frame rate of $2000 \mathrm{fps}$ was used. A technique of image processing was developed to determine the maximum droplet spreading ratio. As the result, the surface tension contributes significantly to maximum spreading ratio. As the droplet surface tension decreases, the maximum spreading ratio increases. The maximum spreading ratio appears when the percentage of the ethylene glycol is $15 \%$ at the temperature of $150^{\circ} \mathrm{C}$. From the visual observation, it is shown that a slower emergence of secondary droplets (droplet splashing) is carried out under a lower surface tension. Hence, surface tension plays an important role on the behavior of emerging secondary droplets. Furthermore, results of the experiments are useful for the validation of available previous CFD models.
\end{abstract}

\section{Introduction}

The phenomenon of liquid droplet impacting onto a solid surface is one of the crucial processes in various practical applications. The impact phenomenon between droplets and solid surfaces can be found, carried out in a cooling process. The cooling process is by spraying liquid droplets or commonly known as spray cooling.

The interaction of droplet with a heated solid surface, will cause some phenomena, such as spreading, rebounding, and splashing. This happens because the increase of temperature can highly affect the surface tension on a material. Therefore the droplet behavior on different test specimens has different phenomena [1].

Bernadin and Mudawar [2] proved that the spray cooling method is able to remove the high heat flux while the desired cooling rate is being controlled. The high rate of heat transfer is considered as an advantage due to it is capable to reduce the size, cost, and complexity of heat transfer apparatus.

One of the properties of colliding-surface droplets, wettability is argued by Deendarlianto et al. [3]. The property is closely related to the heat transfer rate that occurred between droplets and solid surface. The wider the area moistened by droplets, the greater the heat transfer rate.
Chandra and Avedisian [1] investigated the effects of solid temperature on droplet impacts with the constant energy of initial impact. When droplets collided a surface, the splashing, spreading, and rebounding can be occurred. Therefore, from this research, it is expected that the variation of surface temperature effects the results.

Riobo et al. [4] mentioned that the non-dimensional diameter of spreading film, often called a spread factor, will change over time. Meanwhile, the changes are divided into four phases: the kinematic phase, the spreading phase, the relaxation phase, and the wetting/equilibrium phase.

Nasser and Sanjeev [5] performed an analysis model of maximum spreading on droplets colliding with a solid object on low Reynolds and Weber numbers, resulting four conditions to consider that would occur to the droplets.

Furthermore, Vishaul et al. [6] reported that ethylene glycol solution has a lower maximum spreading due to its higher surface tension rate than propylene glycol. The effects of surface tension on maximum spreading factors decreases as the impact speed increases. The water droplets spread as much as acetic anhydride droplets despite it has a half surface tension value than water. According to the number of oscillations, it continues

\footnotetext{
* Corresponding author: afiel165@gmail.com
} 
further with ethylene glycol droplet oscillating for a much longer time than propylene glycol.

Cossali et al. [7] conducted experiments by using different liquids to compare pure water with waterglycerin mixture. The experimental condition showed that there is a viscosity effect on the spreading and breaking-up behaviors of secondary droplet. By adding glycerin, the viscosity will increase, the Reynolds number and the transfer of convection heat from the surface decreases.

Although an agreement of research on the dynamics of single droplet colliding with a solid surface can be reached, researches on the phenomenon of multiple droplets is still limited. In this research, the heat transfer and the visualization of the spreading and recoiling phenomena of multiple droplets while colliding with a flat surface of stainless steel at a surface temperature of $100-200^{\circ} \mathrm{C}$ with a moderate Weber number will be done. Furthermore, the surface tension effects on the different spreading ratios of liquid produced by multiple droplets are also compared in this research.

\section{Research methodology}

The experimental apparatus used in the present experimental study is similar to that of previous work [8] as shown in Figure 1. An induction stove was used to heat the specimen. The temperatures were maintained at $100^{\circ} \mathrm{C}, 150^{\circ} \mathrm{C}$, and $200^{\circ} \mathrm{C}$. The surface temperature was measured by utilizing a thermocouple. Droplets were dropped onto a heated surface by using a nozzle. The droplet size was considered constant at $2.8 \mathrm{~mm}$. The droplet frequency was set with a control valve on 250 drop/minute. The height between the nozzle and the heated surface was $50 \mathrm{~mm}$, producing a moderate Weber number.

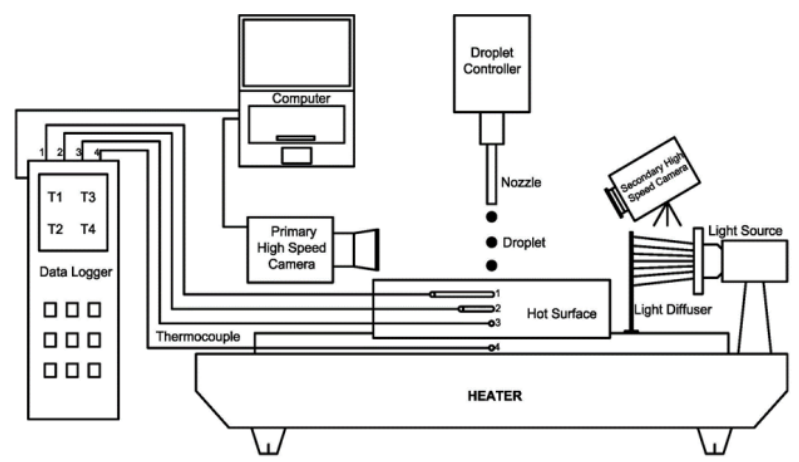

Fig. 1. The schematic drawing of experimental apparatus [8].

The behaviors of droplet impact were observed by using a high speed video camera with a frame speed of $2000 \mathrm{fps}$. The technique of image processing was applied to process the camera data which are successfully captured by the high speed camera. Spreading ratio $(\beta)$ is a comparison between the initial diameter of the droplets and the diameter of the wetting droplets when spreading (spread).

Where:

$$
\beta=d / D
$$

$\beta=$ spreading ratio

$\mathrm{D}=$ Initial diameter droplet $(\mathrm{mm})$

$\mathrm{d}=$ Wetting area diameter $(\mathrm{mm})$

Materials used in the present experiments were stainless steel with variations of ethylene glycol fluid.

Table 1. Surface tension test results.

\begin{tabular}{ll}
\hline Liquid & Surface Tension \\
\hline Water + EG 0\% & $70,1 \mathrm{mN} / \mathrm{m}$ \\
Water + EG 5\% & $59,1 \mathrm{mN} / \mathrm{m}$ \\
Water + EG 15\% & $51,3 \mathrm{mN} / \mathrm{m}$ \\
\hline
\end{tabular}

In the present study, the experimental conditions were as follows; water + ethylene glycol: $0 \%, 5 \%$ and $15 \%$. Working fluids: water + ethylene glycol. As a result the values of surface tension varies. This indicates the concentration and distribution of surfactant in the test fluids are almost uniform. Consequently, the effect of dynamic surface tension in our experiments can be neglected. Variations of surface tension were proved based on visual observations and tests of surface tension with some variations of ethylene glycol, shown in the table of test results Table 1 .

\section{Results and discussion}

To simplify the explanation in this paper, we use some abbreviations for the surface tension characteristics as follows: $\mathrm{EG} 0 \%$, EG 5\% and $\mathrm{EG} 15 \%$, shown in the table of test results Table 1 .

\subsection{Visualization of multiple droplet impact dynamics at the surface temperature of $100^{\circ} \mathrm{C}$}

From Figure 2 can be seen the initial spreading duration of the calculation. Duration spreading marked by the beginning of the process that is currently going on enlargement spreading wetting diameter. The surface temperature of $100{ }^{\circ} \mathrm{C}$, the smaller the surface tension the larger the spreading diameter. Maximum spreading on EG $0 \%$ occurred at $\mathrm{t}=255 \mathrm{~ms}$, EG $5 \%$ occurred at $\mathrm{t}=$ $322.5 \mathrm{~ms}$ and EG 15\% occurred at $\mathrm{t}=260 \mathrm{~ms}$. Process of recoiling on EG $0 \%$ occurred at $\mathrm{t}=262.5 \mathrm{~ms}$, EG 5\% occurred at $\mathrm{t}=332.5 \mathrm{~ms}$ and EG $15 \%$ occurred at $\mathrm{t}=270$ $\mathrm{ms}$. In Figure 3 that at the beginning of the spreading ratio was observed spreading ratio constant, at a certain time after the collision both spreading ratio increases. The whole collision phenomenon measured the spreading ratio of the wetting region. The higher the mixture of ethylene glycol, the greater the spreading ratio, because the greater the mixture of ethylene glycol will decrease the observed surface tension value. 


\begin{tabular}{|c|c|c|c|}
\hline \multirow{2}{*}{ Description } & \multicolumn{3}{|c|}{ Material $=$ Stainless Steel } \\
\hline & EG $0 \%$ & EG 5\% & EG $15 \%$ \\
\hline \multirow{2}{*}{$1^{\text {st }}$ impact } & & & \\
\hline & $\mathrm{O} \mathrm{ms}$ & $\mathrm{O} \mathrm{ms}$ & $0 \mathrm{~ms}$ \\
\hline \multirow[t]{2}{*}{ spreading } & & & \\
\hline & $2,5 \mathrm{~ms}$ & $2,5 \mathrm{~ms}$ & $2,25 \mathrm{~ms}$ \\
\hline \multirow[t]{2}{*}{ max spreading } & forses & $8 \pi$ & \\
\hline & $6,5 \mathrm{~ms}$ & $9 \mathrm{~ms}$ & $10 \mathrm{~ms}$ \\
\hline \multirow{2}{*}{ recoil } & & & \\
\hline & $16,5 \mathrm{~ms}$ & $16,5 \mathrm{~ms}$ & $18 \mathrm{~ms}$ \\
\hline \multirow[t]{2}{*}{$2^{\text {nd }}$ impact } & & ㅇ. & \\
\hline & $241,5 \mathrm{~ms}$ & $315 \mathrm{~ms}$ & $250 \mathrm{~ms}$ \\
\hline \multirow[t]{2}{*}{ spreading } & $\Leftrightarrow$ & S7 & $\Leftrightarrow$ \\
\hline & $244,5 \mathrm{~ms}$ & $317,5 \mathrm{~ms}$ & $252,5 \mathrm{~ms}$ \\
\hline \multirow[t]{2}{*}{ max spreading } & & $=0$ & $\Rightarrow$ \\
\hline & $255 \mathrm{~ms}$ & $322,5 \mathrm{~ms}$ & $260 \mathrm{~ms}$ \\
\hline \multirow[t]{2}{*}{ recoil } & & & \\
\hline & $262,5 \mathrm{~ms}$ & $332,5 \mathrm{~ms}$ & $270 \mathrm{~ms}$ \\
\hline
\end{tabular}

Fig. 2. The phenomena of spreading and recoiling on multiple droplets with variations of ethylene glycol at the temperature of $100^{\circ} \mathrm{C}$.

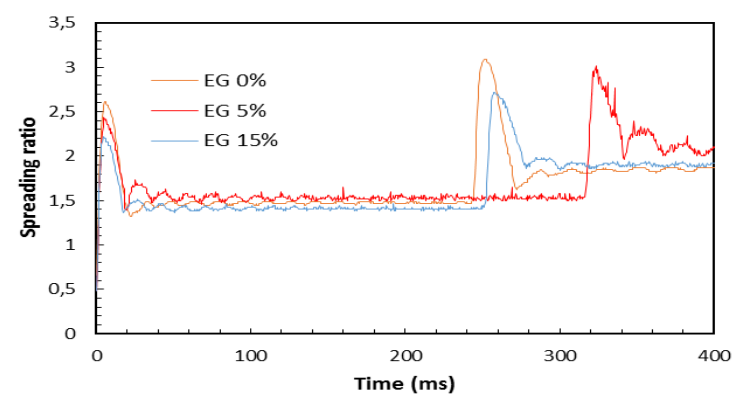

Fig. 3. The spreading ratio as a time function with variations of ethylene glycol at the temperature of $100^{\circ} \mathrm{C}$.

\subsection{Visualization of multiple droplet impact at the surface temperature of $150^{\circ} \mathrm{C}$}

The phenomena occurring in the first droplet at the temperature of $150^{\circ} \mathrm{C}$ are spreading, recoiling, and secondary droplet (Figure 4). The new phenomenon, split, occurs at this temperature. Droplets are split to be one main droplet and several smaller droplets, or the secondary droplets. The split occurs when $\mathrm{T}_{\text {wall }}>\mathrm{T}_{\text {sat }}$ liquid, forming bubble boiling droplets. Bubbles generated by the heat transfer from the specimen surface will develop and lean towards the droplet surface, hence producing the secondary droplets as suggested by Cossali et al., [7]. The fastest secondary droplet occurs at the surface tension of $70.1 \mathrm{mN} / \mathrm{m}$ or at $\mathrm{t}=183 \mathrm{~ms}$ (Figure 4). It is because the higher the surface tension, the faster the emergence of secondary droplets. While the smaller the surface tension, the greater the spreading ratio (Figure 5).

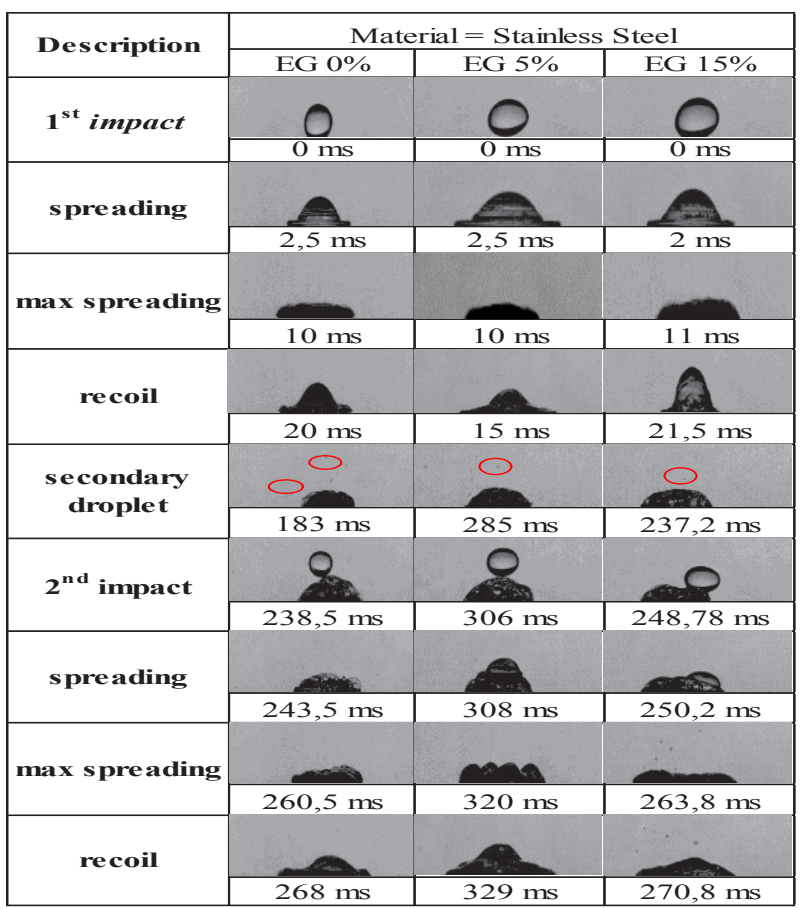

Fig. 4. The phenomena of spreading, recoiling, and secondary droplet at the multiple droplets with variation of ethylene glycol at the temperature of $150^{\circ} \mathrm{C}$.

Impacts between the second and first droplets of all surface tension variations have a similar pattern.

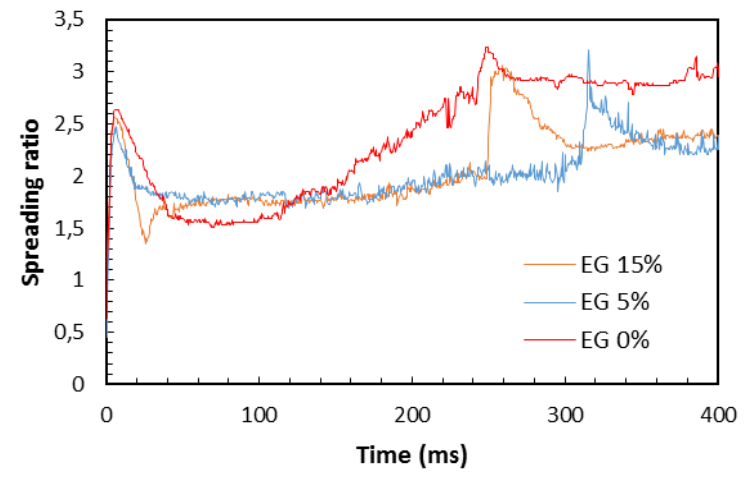

Fig. 5. The spreading ratio as a time function with variations of ethylene glycol at the temperature of $150^{\circ} \mathrm{C}$.

\subsection{Visualization of multiple droplet impact at the surface temperature of $200^{\circ} \mathrm{C}$}

Figure 6 shows the phenomena of spreading, recoiling, and secondary droplet when the surface temperature was $200^{\circ} \mathrm{C}$. In the first droplet, the lower the surface tension, the greater the spreading ratio. Meanwhile, the higher the surface tension, the faster the emergence of secondary droplet. Figure 7 the spreading ratio as a time function with variations of ethylene glycol at the temperature of $200^{\circ} \mathrm{C}$. The bouncing phenomenon does not occurred by using different liquids, comparing pure water with the mixture of water and glycerin. The experimental condition shows that there are viscosity effects on the spreading behavior and break-ups on the secondary droplet. By adding the glycerin, the viscosity increases; while the Reynolds number and the convection heat 
transfer from a surface to liquid decrease as reported by Cossali et al., [7].

\begin{tabular}{|c|c|c|c|}
\hline \multirow{2}{*}{ Description } & \multicolumn{3}{|c|}{ Material $=$ Stainless Steel } \\
\hline & EG $0 \%$ & EG 5\% & EG $15 \%$ \\
\hline \multirow[t]{2}{*}{$1^{\text {st }}$ impact } & & & \\
\hline & $\mathrm{O} \mathrm{ms}$ & $\mathrm{O} \mathrm{ms}$ & $\mathrm{O} \mathrm{ms}$ \\
\hline \multirow[t]{2}{*}{ s preading } & & & \\
\hline & $2 \mathrm{~ms}$ & $1,5 \mathrm{~ms}$ & $1,5 \mathrm{~ms}$ \\
\hline \multirow[t]{2}{*}{ max spreading } & & & \\
\hline & $11 \mathrm{~ms}$ & $8,99 \mathrm{~ms}$ & $7,5 \mathrm{~ms}$ \\
\hline \multirow[t]{2}{*}{ recoil } & & & \\
\hline & $19 \mathrm{~ms}$ & $14,9 \mathrm{~ms}$ & $15,5 \mathrm{~ms}$ \\
\hline \multirow[t]{2}{*}{$2^{\text {nd }}$ impact } & & & 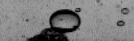 \\
\hline & $228 \mathrm{~ms}$ & $335,2 \mathrm{~ms}$ & $245,5 \mathrm{~ms}$ \\
\hline \multirow[t]{2}{*}{ spreading } & & & \\
\hline & $232 \mathrm{~ms}$ & $337,2 \mathrm{~ms}$ & $248 \mathrm{~ms}$ \\
\hline \multirow[t]{2}{*}{ max s preading } & & & 8 \\
\hline & $244,5 \mathrm{~ms}$ & $344,7 \mathrm{~ms}$ & $253 \mathrm{~ms}$ \\
\hline \multirow[t]{2}{*}{ recoil } & & & \\
\hline & $250 \mathrm{~ms}$ & $359,6 \mathrm{~ms}$ & $264,5 \mathrm{~ms}$ \\
\hline
\end{tabular}

Fig. 6. The phenomena of spreading, recoiling, secondary droplets, and bouncing on multiple droplets with variation of ethylene glycol at the temperature of $200^{\circ} \mathrm{C}$.

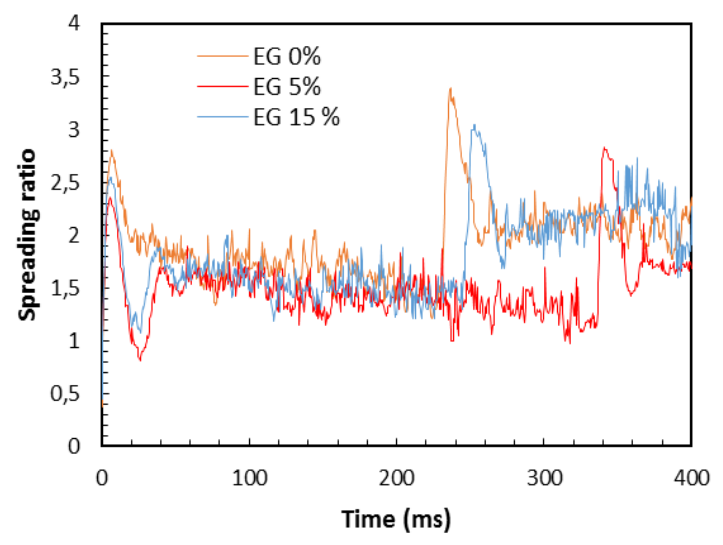

Fig. 7. The spreading ratio as a time function with variations of ethylene glycol at the temperature of $200^{\circ} \mathrm{C}$.

\section{Conclusions}

The ethylene glycol concentrations of $0 \%, 5 \%$ and $15 \%$ on the dynamics behavior of successive multiple droplets is investigated experimentally. It is found that changes in surface tension at surface temperature resulted in different behavior than droplet collisions. The maximum spreading ratio appears when the percentage of the ethylene glycol is $15 \%$ at the temperature of $150^{\circ} \mathrm{C}$. It is clear that the present study has been conducted for all surface temperatures shows the effect of the same surface tension on the dispersion ratio, the smaller the surface tension, the greater the spreading ratio. Hence, surface tension plays an important role on the behavior of emerging secondary droplets.

\section{References}

1. S. Chandra, C.T. Avedisian, "On The Collision Of A Droplet With A Solid Surface," Proceedings Of The Royal Society A: Mathematical, Physical and Engineering Sciences, 431 (1884), 13-41 (1991)

2. J.D. Bernadin, I. Mudawar, "Film Boiling Heat Transfer of Droplet Stream and sprays," International Journal of Heat and Mass Transfer, 40 (11) 579-593 (1997)

3. Deendarlianto, T. Yasuki, H. Sumitorno, Indarto, A. Widyaparaga, S. Kamal, Purnomo, M. Kohno, "Effect of Static Contact Angle on The Droplet Dynamics During The Evaporation of a Water Droplet on The Hot Walls" International Journal of Heat and Mass Transfer, 71, 691-705 (2014)

4. R. Rioboo, M. Marengo, C. Tropea, "Outcomes from A Drop Impact on Solid Surfaces" Journal of Fluids Engineering, 132 (6), 112-124 (2002)

5. N. Ashgriz, S. Chandra, Handbook of atomization and sprays: Theory and Applications (Springer, London, 2010)

6. V. Ravi Effects on Interfacial and Viscous Properties of Pure Liquids and Polymeric Solutions on Drop Spread Dynamics (Thesis, Department of Mechanical, Industrial and Nuclear Engineering, Anna University, India, 2011)

7. G.E. Cossali, M. Marengo, M. Santini, "Secondary atomisation produced by single drop vertical impacts onto heated surfaces," Experimental Thermal and Fluid Science 29, 937-946 (2005)

8. T. Wibowo, A. Widyatana, S. Kamal, Indarto, Deendarlianto, "The effect of pressure and frequency on the dynamic behavior and evaporation time of successive water droplets impacting onto hot surface," MATEC Web of Conferences 154, (2018) 